\title{
Simulation Games As Educational Learning Method in Engineering Careers
}

\author{
Leonardo Adán Douglas Costucica \\ Department of Mechanical Engineering, Facultad Regional Buenos Aires, Universidad Tecnológica Nacional, Buenos Aires 1179, \\ Argentina
}

Received: April 01, 2015 / Accepted: April 17, 2015 / Published: April 25, 2015.

\begin{abstract}
The challenges of today's world require college students have different skills and know how to apply the knowledge acquired to solve new situations. The traditional mode of teaching with lectures, still present in many subjects of the engineering, seems to favor the development of the necessary skills, as active use of knowledge required [1]. However, they are using simulation games as an educational method in many universities in the world for the advantages they present for learning and the development of various skills, to simulate specific situations of professional activity [2]. This paper presents some background and requirements that games must meet educational purposes and propose their use in subjects related to economics, management and organization of production engineering programs where you can teach and learn from building products with simple items like cardboard paper on the theory of constructionism to build a product where people are building theories and knowledge in the mind [3]. The use of games is not widespread in universities in Argentina, however you can generate more motivating learning situations as it leaves the board becoming less abstract and more concrete learning. Classroom climate changes as students take a more participatory role and the teacher intervenes as a guide or facilitator of learning. This work could motivate teachers and researchers to promote their use in teaching and in future research to evaluate the potential of its use as a learning tool.
\end{abstract}

Key words: Simulation, game, teaching, learning, educational method.

\section{Introduction}

With the advancement of science and technology, new forms of production and the effect of globalization, there have been major social, political, economic and societal transformations knowledge. Given these changes new skills to have the skills to interpret and solve the problems currently present are necessary. This poses a major challenge to higher education, especially university, which has seen the need to rethink their curriculum seeking to generate responses. In particular, the engineering programs in the country (based on an approach that strengthens professional practical training graduates) seeking rethink and include activities that stimulate the capacity for analysis, synthesis and critical thinking of the student,

Corresponding author: Leonardo Adán Douglas Costucica, professor, M.Sc., research field: simulation games for engineering education. E-mail: lcostucica@frba.utn.edu.ar. awaken your creative vocation, train for teamwork and assessment of alternatives. The assessments in this area should address, in an integrated manner, the acquisition of knowledge, attitudes and skills training to find information and solve real problems [4].

Despite the progress that research on learning styles and teaching have resulted in education, general teaching mode has not changed, remaining unchanged compared to the changes that have occurred in society. Is it possible to think of a possibility of change in a crisis of modern education? Is it conceivable that an educational innovation can open new doors to knowledge? Why not? Drawing on the words of Gardner [5], the same material can be presented in many different ways, appealing to multiple strategies that allow students to assimilate based on their capabilities and leveraging their strengths.

In various universities worldwide as of 
Pennsylvania-Wharton School of Economics and Business, University of Navarra in Spain and the University of the Andes (Colombia), managerial games are used to secure areas such as economics, marketing, HR or finance [6]. It is known to use the game and simulation as a teaching resource, used in teaching subjects like math or foreign language. Other experiences, have the advantages of using games in education, where students gain an understanding of the tasks to develop, feedback decisions, "learn by doing”, increase the speed of learning, improve retention and memorization of concepts and encourage group communication, discussion and decision making [7].

Based on this knowledge, the present study aims to show some learning theories in which the games are based educational purposes and present some guidelines to follow for your design. Finally, some conclusions as to motivate their use and encourage research lines for those who wish to venture into the use of this methodology are presented.

\section{Historical Development of Simulation Games and Typology}

The origins of simulation games dating back to 3000 $\mathrm{BC}$ and are located in India and China. It was war games like Go y el Chaturanga ${ }^{1}$ which seems to come chess, where players had to deploy all their tactical skills to defeat the opponent.

Evidence many centuries before Christ, in ancient Greece, Asia Minor, Persia and India, the existence of tactical games such as ches or checkers ${ }^{2}$ [8]. In ancient Rome, remains of various war games were also

\footnotetext{
${ }^{1}$ Go is played with black and white stones are placed in free intersections of a grid of $19 \times 19$ lines where the goal is to try to control a board larger portion, where you can capture a stone if it is completely surrounded by stones the opposite color. The Chaturanga seems to be the game that comes chess.

2 The pharaoh Ramses II was painted with a checkerboard and, similarly, in many Egyptian tombs and excavations found figures and graphical representations of soldiers and weapons and game boards. An example is illustrated in the book of the dead, where rituals are listed to access the beyond, and in which the deceased appears playing a game of a set of typical table in Ancient Egypt, called "Senet" with an invisible opponent (Steiner, 1998).
}

found, encumbered as the boards 57 on paving stones found near the city of Seville and the game of war strategy called "Ludus Latrunculorum” [9].

In his 1995 work, Jones [cited in Ref. [8] considered later in the seventeenth century, chess games went on to become a recruiting tool and training of troops in all Europe, where the reactions could be in the present or future troops of the various armies asking them how they would react in a similar situation could occur in reality was evaluated.

In World War countries like Germany, France and Japan simulation games used as a tool to assess military strategies [10]. After the Second World War, simulation games went to the field of business hand many retired officers who held managerial positions in various companies. The games will start to use as a tool for staff training and thereafter are many theories and applications of simulation games in the educational field and in the business world as well as in many other fields such as medicine, psychology, etc.

From the 1950s, simulation games that applied to the business world began to spread to schools of economics and business worldwide. It is in 1968 in England when the first game used for teaching purposes in the classroom and from that moment, the numbers of games companies begin to grow rapidly recorded.

In 1961, more than 100 games company that are used by more than 30,000 executives are designed. In 1980, The Guide to Simulations / Games for Education and Training describes 228 games company. In the academic year 1985-1986, it was estimated that in 1900, more than 8,755 university professors used games company which represents $95.1 \%$ of accredited universities in the United States for the specialty of Management [8].

Meanwhile, in the typology of the different simulation games, as in Ref. [11], it is possible to distinguish four distinct varieties of simulation: case studies, role-playing or "role playing” simulation-game 
simulation using a machine.

For each case, the level of abstraction will intensify as it moves from case studies through role-playing-game or simulation to simulation by a machine [11]. So you may recognize:

- The case study. It is a technique that presents a situation through "historical" roles elected creating a descriptive relationship, in which different combinations of real world data, narratives, tapes or films, etc. are used. It has a high degree of relationship to reality due to the use of a large amount of material from the real world, is why what is considered a simulation although not commonly think of as such:

- Representation of paper or "role playing". It involves not only the analysis or discussion of the information and case studies, but also requires that participants represent situations using a database provided as a starting point. Participants should develop a sequence of events shaping the data and setting the facts and spontaneous performance. Strangers must pass the problem to be part of it.

- Simulation-game. It is located at a higher level of abstraction and that means that is halfway between case studies and role-playing on one hand, and computer simulation on the other. It is considered less abstract than computer simulation, but is more complete than the role-playing because it depends more formalized procedures and more structured relations. Try to represent the essence of a situation and most games aim to understand the process of decision making that involves both qualitative and quantitative elements.

- The simulation by computer. This type is supported in math. The probability theory, game theory and other associated mathematical techniques are used to incorporate elements of chance in simulated activities, which need or require to be processed by a calculator or computer. Is designed to provide responses only to the understanding of processes, and accordingly, human participation, the program as a response related to the result that occurs is limited to an initial development.

\section{Theories of Learning and Games}

The incorporation of the game as a teaching method has its foundation in learning theories emerged in the early twentieth century. The most important contributions come from dynamic psychology of William James, the creation by Claparade European Institute of Applied Psychology who will lay the foundations of genetic theory of Piaget.

The traditional way of teaching raises some forms of teacher-student relationship based on a predominantly or all dirigisme by the teacher. The games take educational purposes movement of the new school the idea that students can direct their own learning tasks, and therefore the teacher should not constantly guide their actions, but rather provide guidance and support to them.

The games allow sensorimotor actions and mental operations, where Piaget postulated that cognitive changes are a result no knowledge of the objects but the manipulation and exploration of reality. Some of his conclusions are concerned about the constructive nature of individual development, the importance of student activity for the development of higher cognitive activities, language, the importance of cognitive conflict or discrepancy between reality and their schemes as a means of generate progress and importance of cooperation for the development of cognitive structures [12].

Another contribution that gives definition and clarity on the position taken is that of Ref. [13], which proposed the importance of social interaction in learning. Vygotsky defines the area "proximal development" as the distance between the zone of actual development and potential. Through a game can generate that zone of proximal development because students from the problem posed by the playful activity can be linked to another higher level of knowledge, be it a peer or teacher.

As to meaningful learning, Ausubel [14] is based on the assumption that people think of concepts. The learner has a cognitive structure that contains clear and 
available processes and concepts which serve to anchor new knowledge. Thus, new knowledge can be learned and retained, to the extent that the subject concepts cognitive structure available to be served, are anchor. Games can create conditions to foster meaningful learning that students have in their cognitive structure of previous concepts that allow him to assimilate the new content, make an effort to establish relationships between new knowledge and he already owns and knowledge are actually used by students when circumstances require game.

In discovery learning guided by the teacher, Bruner [15] proposed that it is he who best can capture the structure of reality. In this case, the teacher's role is that of an expert who controls the development of knowledge through guidance and careful scaffolding. Bruner's theory of games takes the following elements: the teacher guides the student discovery through a pose and setting out the problem with job support and guidance of the learning process. The student develops their capacity to capture, process and transfer what they learn by developing the ability to solve the problem posed by the games.

\section{The Constructionism and Play}

Constructionism is a theory developed by Seymour Papert and his colleagues at MIT (Massachusetts Institute of Technology) in Cambridge, Massachusetts (USA). These developed in the mid-80s, the LEGO TC Logo combining computing language known LEGO construction toys. Papert [16] extends the constructivist theory of Piaget [17] to the fields of learning theory and education, developing constructionism. In this, it shows that the constructivist learning happens especially well when people are involved in building a product, something external to them. When building a product on the outside world, people are building theories and knowledge in mind.

Papert [16] states that "to solve a problem looking for something like that already understand,” suggesting the use of prior knowledge in resolving current conflicts and with them the construction of new knowledge.

Importantly, not only the construction process making learning meaningful for the learner. Both the process of creating the final product should be shared with others to make learning robust. This occurs when talking with others or explain or show diagrams or schematics [18].

From the repetition of experience and observation of children, Papert concluded that "learning will not improve just finding better ways for teachers to teach, but providing students better opportunities to build”. Constructionism is not just a theory on how to facilitate learning but a way of turning ideas and formal and abstract relationships into more concrete, more visual, more tangible, more controllable and therefore more readily comprehensible. When "we reason by" liberated creative energy, ways of thinking and ways of seeing things that otherwise would never be released. This theoretical approach is the use for this research. This theoretical approach most concepts is adopted.

Based on this theory proposes games are proposing to teach different subjects in engineering programs, using simple items such as cardboard or paper products where the production line, a company or a market of supply and demand is simulated to see concepts are built of subjects in the economic area as costing, quantities of raw materials and labor used in manufacturing, productivity rates or determination of income. In matters of organization and industrial planning can see concepts methods and production times, line capacity and bottleneck concept or concepts of lean manufacturing. Through this methodology longer abstract concepts and become more specific to the student, to be able to work and play with them. Classroom climate changes and the teacher can act as a mentor or facilitator of learning, based on the interests of each student.

\section{Fundamentals and Game Requirements}

The rationale underpinning the proposal for the 
design of a game can be based on educational purposes proposed by Normann [19]:

- Provide a high interaction and feedback to participants;

- Have specific goals and procedures;

- Generate a continuous feeling of challenge;

- Encourage participants;

- Provide a sense of direct involvement by implementing own activity to perform tasks.

Some requirements for the design of a game based on proposals by various authors compiled by Reyes [6] are proposed:

(1) Retake existing games and incorporate concepts of the subject to develop, seeking to have clear rules and seek to combine the playful factor for educational purposes;

(2) Develop social skills such as communication, teamwork, conflict resolution and work under pressure through the simulation of a part of reality as proposed tactical decision games [20];

(3) Define the learning objectives expected participants during the game design, as they influence the game mechanics to implement, as proposed in the Risk Management Game [21];

(4) Give participants play a validation mechanism for compliance with the learning objectives to assess the evolution of the participants in the assimilation of concepts [22];

(5) Get feedback from participants regarding factors such as degree of realism, level of fun and simplicity of the game looking for further improvement and refinement of design;

(6) Define clear and precise rules of the game to avoid confusion among participants [23];

(7) Empowerment and autonomy players in game development for active members of the learning process feel, enhancing their motivation against the proposed activities, as suggested in Ref. [24] in their work on designing educational games.

\section{Conclusions}

Games are used for educational purposes in many universities in the world for quite a while. Also reviewing the history the importance of using the game is recognized educational purposes since ancient Greece as it was considered that encouraged learning and preparing children for activities that will develop in adulthood. But virtually no history of its use today as an educational method in courses of undergraduate and graduate universities in our country. They are used in some areas or disciplines in learning mathematics and foreign languages, but has not spread use in engineering careers

In general, the teacher tends to reproduce the teaching methods he has received in his training. This is not conducive to finding innovative methods to assign ownership and control of the teacher to the students. Not rethink teaching practice that continues to perpetuate obsolete ways of teaching unresponsive to the needs of today's society.

The game can help review own practice, appealing to the creativity to find new ways to raise a class, where you can experience, create, think class and entusiasmase another approach to the task. Through this new practice a teacher can experience something new, to rebuild your knowledge enriching and transforming their ways of thinking and acting.

The game lets imagine otherwise, the questions that may arise, possible inconvenience and possible answers. However, to make the game that presents new situations even for its designer, situations not covered during design produced by free behavior of players when the game. The commitment and involvement with the task of the students is stimulated through play. It is important to consider that teachers carry forward this methodology will have to be more flexible to have to face teaching situations changing and unpredictable as those raised by a learning game. This involves reformulating the role of teachers closer to a counselor or facilitator of learning.

The design activity of this resource can interact with other teachers of the subject for their opinions regarding content and as raise the issue. This marks a 
difference from what often represents the work of a teacher, solitary and individualistic. In order to strengthen this methodology so it can be carried forward in a course is necessary for the teacher himself was involved from concept and part of the game design to assume it as their own. It is crucial to their commitment and understanding of teaching resource. Therefore, it would be desirable to invite other teachers of the course to play the game to understand how it works and they experience it in their own courses to enable them to contribute their views from new user experiences. The more participatory design and make use of this resource would spread so it can be implemented in different subjects.

\section{Acknowledgments}

The author of this paper would like to thank to Milena Ramallo for their assistance in the preparation of this work.

\section{References}

[1] Perkins, D. 1997. Smart School. Buenos Aires: Edit. Gedisa.

[2] Torre, S. Ora an innovative model to learn the medium. Octahedron University. 1997.

[3] Papert, S. 1987. Challenge Your Mind. Buenos Aires: Edition Galapagos.

[4] Resolution 1232-1201. 2001. Ministry of Education

[5] Gardner, H. 1983. States of Mind: The Theory of Multiple Intelligences. New York: Basic Books.

[6] Duque, R. D. 2011. "Designing a Game Based on Experiences and Educational Support for the Development of Competition Teamwork.” Master thesis, University of Colombia.

[7] Gómez, M. C. 2010. “Defining a Method for Designing Games Aimed at Developing Managerial Skills and Business Training Strategy.” Master thesis, University of Colombia.

[8] Garcia, C., and Watts, F. A. 2007. "Historical Perspective Simulation Game as a Teaching Strategy: The War on
Classroom LSP.” Iberica 13: 65-84.

[9] Steiner, A. 1998. “Check to Pharaoh.” Newton 4: 39-40.

[10] Hausrath, A. 1971. Simulations Risk for War, Business and Politics. New York: Mc Graw Hill.

[11] Taylor, J. 1983. “Guide on Simulation and Gaming for Environmental Education.” UNESCO-UNEP. http://unesdoc.unesco.org/images/0005/000569/056905so .pdf.

[12] Pérez, G. 1992. Gimeno Sacristan. Understand and Transform Teaching. Buenos Aires: Editorial Morata.

[13] Vygotsky, L. S. 1991. The Problem of Development in Structural Psychology. Critical Study. Madrid: Learning Visor.

[14] Ausubel, D. P. 1963. The Psychology of Meaningful Verbal Learning. New York: Grune and Stratton.

[15] Bruner, J. 1984. Action, Thought and Language. Madrid: Alliance.

[16] Papert, S. 1987. Challenge of Mind. Buenos Aires: Ediciones Galapagos.

[17] Piaget, J. 1952. The Origin of Intelligence in Children, 2nd ed. New York: International Universities Press.

[18] Murillo, A., and Saxe, E. 2004. "Constructionism: Objects for Thinking, Public Entities and Microworlds.” Investigative News Electronic Journal of Education 4 (1)" $1-12$.

[19] Normann, R. 1993. "From Value Chain to Value Constellation: Designing Interactive Strategy.” Harvard Business Review 71 (4): 65-77.

[20] Crichton, M., and Flin, R. 2003. "Training for Emergency Management: Tactical Decision Games.” Journal of Hazardous Materials 88: 255-66.

[21] Taran, G. 2007. "Using Games in Software Engineering Education to Teach Risk Management.” Presented at the 20th Conference on Software Engineering Education \& Training, Dubin, Ireland.

[22] Zapata, C., Duarte, M. 2008. "The Game Consistency: A Teaching Strategy for Software Engineering.” Journal Engineering University of Zulia 31 (1): 1-10.

[23] Tollefsrud, J. 2006. “The Educational Game Editor: The Design of a Program for Making Educational Computer Games.” Ph.D. thesis, Norwegian University of Science and Technology.

[24] Denis, G., and Jouvelot, P. 2005. "Motivation-Driven Educational Game Design: Applying Best Practices to Music Education.” Presented at the ACE '05, Valencia, Spain. 